\title{
Constrained consumption shifting management in the distributed energy resources scheduling considering demand response
}

\author{
Pedro Faria, Zita Vale, Jose Baptista
}

\begin{abstract}
A B S T R A C T
Demand response concept has been gaining increasing importance while the success of several recent implementations makes this resource benefits unquestionable. This happens in a power systems operation environment that also considers an intensive use of distributed generation. However, more adequate approaches and models are needed in order to address the small size consumers and producers aggregation, while taking into account these resources goals. The present paper focuses on the demand response programs and distributed generation resources management by a Virtual Power Player that optimally aims to minimize its operation costs taking the consumption shifting constraints into account. The impact of the consumption shifting in the distributed generation resources schedule is also considered. The methodology is applied to three scenarios based on 218 consumers and 4 types of distributed generation, in a time frame of 96 periods.
\end{abstract}

Keywords:

Demand response

Distributed generation

Load shifting

Resource use optimization

Virtual Power Player

\section{Introduction}

Demand Response (DR) is usually defined as the "Changes in electric usage by end-use customers from their normal consumption patterns in response to changes in the price of electricity over time, or to incentive payments designed to induce lower electricity use at times of high wholesale market prices or when system reliability is jeopardized" [1] and it has been largely explored in the context of the operation of electricity markets at higher levels, and also for the improved technical operation of power systems, namely at the lower voltage levels [2].

Several successful implementations of DR programs in real market and power systems can be found in [3], where the DR programs' implementation around the world is analysed in terms of electricity markets integration. In [4], it is presented a review on the DR integration in smart grids, showing the current success cases and the barriers. However, the full integration of DR in a future more competitive context can only be achieved by intensive participation of small size DR resources [5-7]. The work presented in [5] focuses on the standpoint of a distribution network operator in the context of a consumption reduction need, whereas the work presented in [6] centres on the dispatch of DR and Distributed
Generation (DG) by a Virtual Power Player (VPP) for the provisions of energy and reserve. In the case of the work presented in [7] the focus is given to the tariffs' definition while addressing the costumers' characterization. In the referred three works it is commonly addressed the small size resources use. Several regulatory efforts have been made in order to make DR a resource comparable to ordinary generation resources, acting in all the opportunities of electricity markets. It is the case of FERC (Federal Energy Regulatory Commission) Order No. 719, which recommends to "Accept bids from demand response resources in their markets for certain ancillary services on a basis comparable to other resources" [8]. Also in Europe, important regulatory changes are being applied [9].

Virtual Power Players (VPPs) are entities that appeared in the sequence of the recent changes in electricity markets and in power systems operation [10]. These entities are able to aggregate small size energy resources and can have several classifications regarding the specific types of resources that are aggregated. A VPP can namely aggregate DR and DG resources, making possible its participation in electricity markets products intended for the participation of large players. A VPP can also own and operate a portion of a distribution network, owning or not the resources there connected [11].

It is possible to find in the recent literature several works that refer to the need of addressing the consumer preferences in the DR programs modeling and definition. The study in [12] focuses on quantifying the Europe potential for DR usage in distinct sectors of activity. With more focus on the end consumers' activity, the 


\section{Nomenclature}

\section{Acronyms}

FERC Federal Energy Regulatory Commission

RSE resources schedule end time

MNP minimum notification period duration

$Z \quad$ advance notification period

\section{Variables}

$P_{D G(t, d g)}$ active power scheduled for the distributed generation source $d g$ in period $t(\mathrm{~kW})$

$P_{D R(i, t, c t)}$ demand power shifted by the consumption cluster $c t$, from period $i$ to period $t(\mathrm{~kW})$

$P_{L o a d(t, c t)}^{N S P}$ non-supplied active power to the consumption cluster $c t$, in period $t(\mathrm{~kW})$

$P_{\text {Supply(t,sp) }}$ active power scheduled for the supplier $s p$ in period $t$ $(\mathrm{kW})$

VPPOC Virtual Power Player Operation Costs (m.u.)

\section{Parameters}

BI total number of backward consumption shifting periods from each period $t$

BT total number of backward consumption shifting periods in the time horizon

$C_{D R(t, i, c t)}$ cost of the consumption shifting to the consumption cluster $c t$, from period $t$ to period $i$ (m.u./kW h)

$C_{D G(t, d g)}^{a} \quad$ quadratic cost component of the distributed generation $d g$, in period $t$ (m.u./kW h)

$C_{D G(t, d g)}^{b}$ linear cost component of the distributed generation $d g$, in period $t$ (m.u./ $\mathrm{kW} \mathrm{h}$ )

$C_{\text {Load }(t, c t)}^{\text {NSP }}$ cost of the non-supplied active power in the consumption cluster $c t$, in period $t$ (m.u./kW h)

$C_{\text {Supply }(t, s p)}$

cost of the power from supplier $s p$ in period $t$ (m.u./ $\mathrm{kW} \mathrm{h}$ )

CtN
$D g N \quad$ total number of distributed generation types

FI total number of forward consumption shifting periods in a specific period $t$

FT total number of forward consumption shifting periods in the time horizon $T$

$P_{L o a d(t c t)}^{\text {Base }}$ initial consumption of each consumption cluster, in period $t(\mathrm{~kW})$

$P_{\text {Load }(t, c t)}^{\text {Max }}$ maximum consumption of each consumption cluster, in period $t(\mathrm{~kW})$

$\operatorname{PMax}_{D G(t, d g)}$ maximum available capacity from the distributed generation $d g$ in period $i(\mathrm{~kW})$

$P M a x_{D R(t, c t)}^{i}$ maximum consumption shifting by the consumption cluster $c t$, to period $i(\mathrm{~kW})$

$P M a x_{D R(t, c t)}^{t}$ maximum consumption shifting by the consumption cluster $c t$, from period $t(\mathrm{~kW})$

$P M a x_{D R}^{t \rightarrow i}(t, i, c t)$ maximum consumption shifting by the consumption cluster $c t$, from period $t$ to period $i(\mathrm{~kW})$

PMax $_{\text {Supply }(t, s p)}$ maximum available capacity from the supplier $s p$ in period $t(\mathrm{~kW})$

SpN total number of consumption suppliers

$T \quad$ total number of periods in the time horizon

$\alpha_{D G}^{M a x} \quad$ maximum contribution of the distributed generation to the energy supply (\%)

$\alpha_{D R}^{\mathrm{Max}} \quad$ maximum total consumption reduction in each single consumption cluster (\%)

$\begin{array}{ll}\text { Indexes } & \\ c t & \text { consumption cluster index } \\ d g & \text { distributed generation type } \\ i & \text { consumption shifted period index } \\ s p & \text { electricity supplier } \\ t & \text { consumption shifting period index } \\ t 0 & \text { beginning of the scheduling horizon }\end{array}$

power quality issues [23]. A study regarding the real implementation of DR and DG can be found in [21].

The mentioned works generally refer to the quantification of the DR potential and DG penetration in distinct systems and/or environmental conditions. The methodology proposed in the present paper goes further on making possible to the consumers to define several consumption shifting and reduction preferences. It also allows the DG resources to be adequately managed together with DR. DG and DR resources' characteristics are taken into account as input parameters and constraints of the optimization model that is developed in order to perform the joint DR and DG's resources scheduling.

The methodology proposed in the present paper is intended to be used by a VPP that aggregates DG and DR resources. One of the main contributions of the present paper concerns the methodological aspect. It has been considered that consumers can reduce the consumption in a certain period and/or shift some of the consumption to several periods before and after the original period. Several time constraints were implemented, as detailed in Section 2. From the DG side, it has been considered the maximum contribution that a certain type of DG can have in the performed resource scheduling. Other main contribution has to do with the definition and implementation of an optimization problem that aims at scheduling the available DR and DG resources. The DG and the DR resources are dispatched according to their operating constraints but also to their prices. The optimization problem aims at minimizing the VPP operation costs, i.e. the remuneration that must be paid to the DG sources and to the DR resources. In this way, whenever a natural sources is a key part of smart grids and microgrids [22]. These concerns also include technical concerns as the case of 
DR event is declared (for one or for several periods, due to power or prices' issues) the available DG and DR resources are optimally scheduled taking into account the implemented constraints which represent the players' preferences.

The implemented DR program belongs to the category of incentive-based DR, in which the consumers are remunerated according to the actual consumption reduction. A capacity payment can also be included in this kind of DR programs [1].

From the past works of the same authors of the present paper one can find related work in [5,6] and [11]. These past works include the optimization of distributed energy resources use, including DG and DR. These works consider the use of DR in a specific period, without considering the shifting of the consumption between periods, and therefore without analysing the impacts of the consumption shifting in the envisaged periods. Also, these impacts were, therefore, not adequately addressing in what concerns the integration with DG. In the case of DG, the unexpected wind power unavailability has not been addressed in the referred past works.

After this introductory section, Section 2 explains the proposed methodology. Then, Section 3 presents the case study and Section 4 includes the obtained results. Finally, Section 5 presents the main conclusions of the work.

\section{Proposed demand response model}

The proposed demand response model has been developed in order to integrate the schedule of both demand response and distributed generation resources in an energy resource management scheme oriented to the Virtual Power Player's (VPP) activities. According to the proposed model, Fig. 1 depicts the resources (DR and DG) aggregation by the VPP. From the supply side, the VPP can use supply resources (Suppliers selling electricity generated out of the VPP network) under specific conditions, namely constrained by the maximum supplier power that is available in each period as well as the respective price. The VPP is also able to make use of the available DG units at its specific power and price parameters in each period. Thus, Suppliers, DG and DR resources are jointly scheduled, also considering the DR prices and constraints. In this way, the VPP assures the fulfilment of the demand's needs, remunerating the consumers for their consumption reduction as well as the DG units for their generation.

From the consumers' side, it is considered that the VPP manages the consumption in an aggregated way, in several consumption clusters (ct). In Fig. 1, it is represented the consumption cluster of maximum index - CtN , the Supplier of maximum index - SpN, and the DG unit of maximum index - DgN. Each one of these is the bound of the generic consumption cluster $c t$, the generic Supplier $s p$, and the generic DG unit $d g$.

In the case of cluster $C t N$, illustrated in the bottom for Fig. 1, the critical periods are represented (according to Fig. 2) in the time horizon, focusing on the consumption changes affecting period $t$. One can shift a part of the consumption from period $t$ to one or several periods before and after $t$. Additionally one can see the consumption reduction in $t$ (without shifting to another periods). A certain DR amount income is verified in period $t$, shifted from period $t 0$. At the end, in period $t$, considering the consumption shifting (incoming and outgoing) and the consumption reduction, the final consumption is lower than the initially expected demand. It is important to note the case of period to in which, after shifting some consumption to period $t$ and receive some other consumption amount form period $t$, the final consumption is higher than the initially expected demand.

The VPP's resources management is addressed in each period, according to the consumption shifting costs for each specific shifting possibility and according to the distributed generation costs. This way, it minimizes the total operation costs for the overall scheduling horizon.

The details of the time constraints concerning the resources scheduling are illustrated in Fig. 2. The proposed DR model considers that the VPP performs the resources schedule for a determined time horizon. The model is flexible in the time advance that the VPP uses to perform the resources scheduling. For example, if the resources' schedule is performed for a time horizon of 1 day ( $24 \mathrm{~h})$, it can be performed, for example, 24 or $12 \mathrm{~h}$ before the beginning of the target day. This way the consumer can be notified on the scheduled consumption shifting details.

According to Fig. 2, several conditions must be verified in the scheduling calculation, notification and implementation processes.

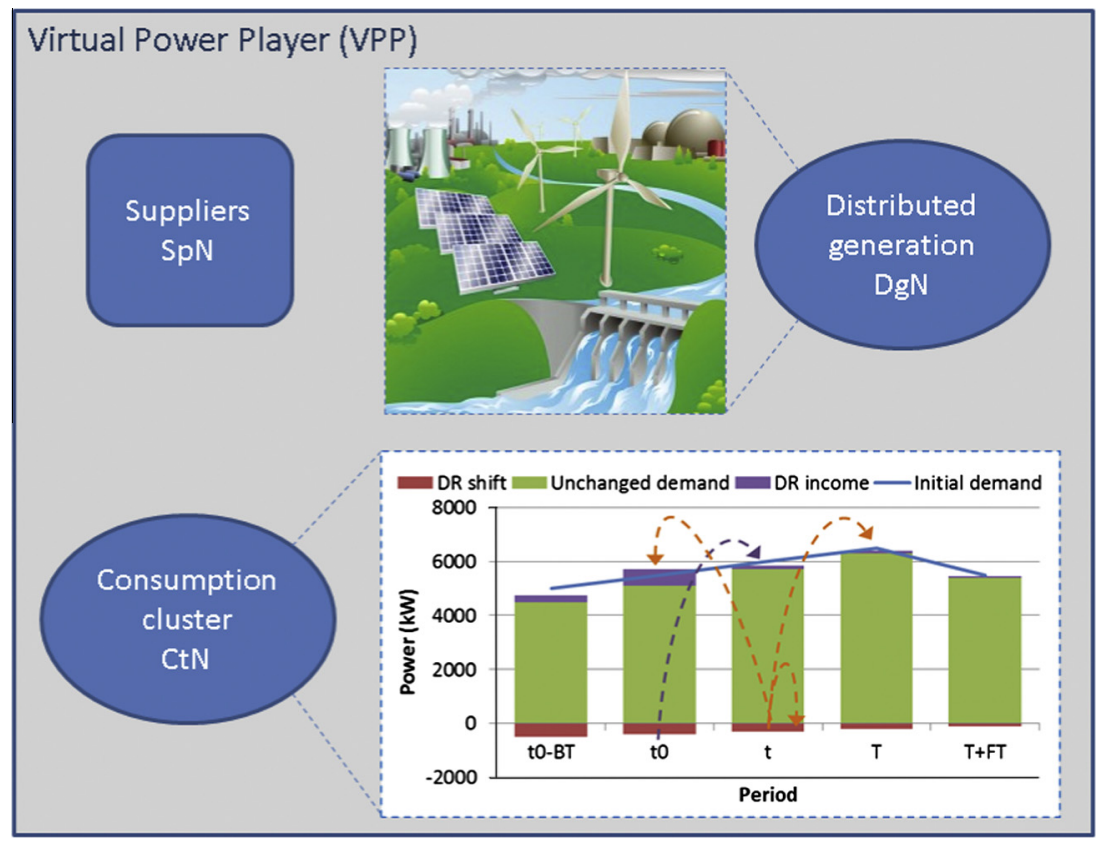

Fig. 1. Diagram of the proposed model - resources' aggregation (DG picture adapted from [24]). 


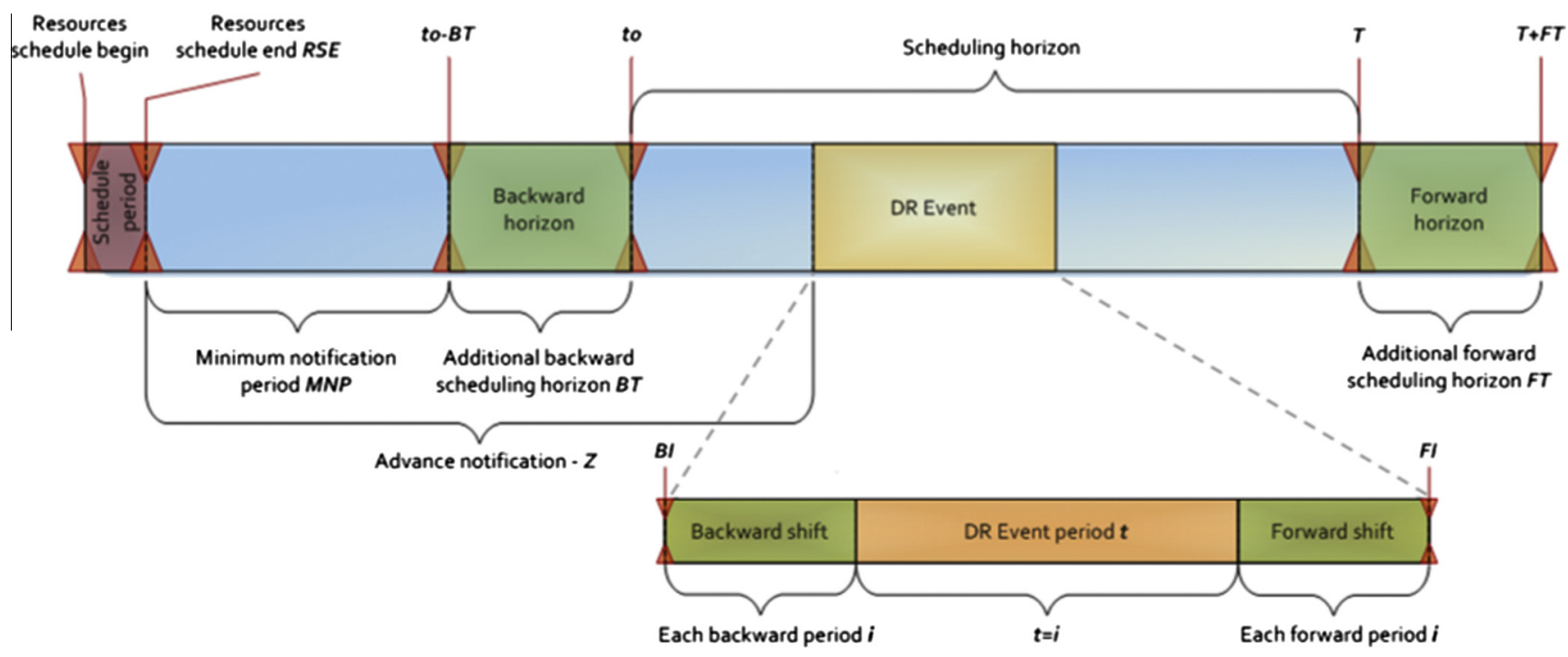

Fig. 2. Diagram of the DR model - time horizons.

It is considered that the resources' scheduling process requires a certain amount of time (schedule period), since the resources schedule begins until it ends (RSE). Assuming as reference the beginning of the scheduling horizon, occurred in $(t 0)$, the time constraints represented in Eqs. (1)-(3) must be satisfied for the periods preceding $t 0$.

$R S E+M N P+B T \leqslant t 0$

$M N P \geqslant 0$

$Z \geqslant M N P$

The proposed model considers that for each period $t$, between $t 0$ and $T$ (the limit of the scheduling horizon), some of the consumption can be shifted to several periods before (backward shifting) and after (forward shifting) $t$. In order to address this, the time slots $t 0-B T$ and $T+F T$ have been included in the model. As in Eq. (1) the sum of the additional backward scheduling horizon (BT) with the minimum notification period (MNP) and with the resources schedule end (RSE) must be higher than 0. Otherwise, the resources' schedule process would begin exactly in $t 0$. In fact, one can avoid $B T$ in this specific context. However, a certain minimum notification period is always needed, as modeled in Eq. (2), so that the consumers are notified about the consumption shifting and the reduction minimization. This way they can manage to change the consumption pattern.

When a specific DR event occurs the consumers must be notified. In this case, it is verified an advance notification $(Z)$, which is always, by definition and according to Eq. (3), higher or equal (in the case that the DR event happens in t0) to MNP. The diagram of Fig. 2 presents one DR event occurring in the scheduling horizon. Each DR event can occur during several consecutive periods. For each one of the DR event periods, it is possible to define the maximum backward shifting $(B I)$ period and the maximum forward shifting $(F I)$ period. Hence, the initial expected consumption in period $t$ can be totally or partially shifted to other periods (between $B I$ and $F I$ ), or simply avoided (the consumption is reduced but not shifted to other periods).

As it is explained in Section 3, the shifting period definition includes the maximum amount of power that can be shifted from a specific period to other periods $i$ (and the consumption reduction in period $t$ ) and the cost associated to each specific shifting opportunity. The proposed DR model considers several constraints in the amount that can be shifted in each specific period or set of periods, for each one of the consumption clusters, and it also considers the energy supply costs and constraints.

\section{Demand response resources schedule optimization}

This section presents the mathematical formulation of the resources' optimal scheduling performed for the periods of the scheduling horizon (from t0 to $T$ ). As explained in Section 2, the consumption shifting can be performed to periods before the beginning of the scheduling horizon (from $t 0-B T$ to $t 0$ ) and to periods after the end of the scheduling horizon (from $T$ to $T+F T$ ). The implemented optimization problem is intended to be used by the VPP in order to take decisions on the scheduling of the distributed generation resources and for the consumption reduction and shifting opportunities.

The objective function of the optimization problem is formulated as represented in Eq. (4). The VPP operation costs are minimized while the resources (distributed generation and demand response) available in each period $t$ are scheduled. The cost of the non-supplied power (NSP) regarding a non-contractual consumption curtailment is also considered. The optimization problem is constrained by the Eqs. (5)-(12).

Minimize

$$
\begin{aligned}
V P P O C= & \sum_{t 0-B T \leqslant t}^{t \leqslant T+F T}\left[\sum_{s p=1}^{S p N} P_{\text {Supply }(t, s p)} \times C_{\text {Supply }(t, s p)}\right. \\
& +\sum_{d g=1}^{D g N}\left(P_{D G(t, d g)}^{2} \times C_{D G(t, d g)}^{a}+P_{D G(t, d g)} \times C_{D G(t, d g)}^{b}\right) \\
& \left.+\sum_{t-B I \leqslant i c t=1}^{i \leqslant t+F I} \sum_{C t N}^{C t N}\left(P_{D R(t, i, c t)} \times C_{D R(t, i, c t)}+P_{\text {Load }(t, c t)}^{N S P} \times C_{\text {Load }(t, c t)}^{\text {NSP }}\right)\right]
\end{aligned}
$$

In each specific period $t$, the shifting periods $i$ are bounded by $t-B I$ and $t+F I$. From the consumer's side, the proposed approach considers the consumption shifting from several specified $c t$ consumption clusters bounded by $C t N$.

The first constraint regards the energy balance in each period, as in Eq. (5). This constraint is applied to each period $t$ in the time slot between $t 0-B T$ and $T+F T$, instead of only considering the 
periods in the scheduling horizon ( $t 0$ to $T$ ). In practice, the base consumption expected for each consumption cluster $c t$, plus the consumption concerning the demand shifted to each period $t$ from other periods $i$, minus the contracted consumption shifting and the non-contracted consumption curtailment must meet the scheduled supplier $s p$ and distributed generation unit $d g$ power.

$$
\begin{aligned}
& \left.\sum_{c t=1}^{C t N} P_{L o a d(t, c t)}^{\text {Base }}-P_{L o a d(t, c t)}^{N S P}+\sum_{t-B I \leqslant i}^{i \leqslant t+F I}\left[P_{D R(i, t, c t)}-P_{D R(t, i, c t)}\right]\right) \\
& =\sum_{s p=1}^{S p N} P_{\text {Supply }(t, s p)}+\sum_{d g=1}^{D g N} P_{D G(t, d g)} ; \quad \forall t 0-B T \leqslant t \leqslant T+F T
\end{aligned}
$$

The set of constraints represented by Eqs. (6)-(11) regards the maximum amount of consumption shifting that can be done between periods. Each one of these constraints is applied to each period between $t 0-B T$ and $T+F T$, and to each consumption cluster $c t$ (with a maximum of consumption clusters $C t N$ ).

In Eq. (6) it is also considered the constraint validation for each shifting period $i$ between the backward shifting limit $B I$ and the forward shifting limit FT. It considers the maximum capacity of consumption reduction that can shifted from period $t$ to period $i$, in each consumption cluster $c t$. It is of upmost importance to note that the period for which the consumption is shifted (period $i$ ) comprises all the periods between $B I$ and $F I$ related to each specific period, including the specific case in which matches the period $t$. In this specific case, one can say that the consumption expected for period $t$ can be shifted to the same period $t$ itself. In this case, we say that it is verified a consumption reduction, instead of a consumption shifting.

$$
\begin{aligned}
P_{D R(t, i, c t)} \leqslant P M a x_{D R(t, i, c t)}^{t \rightarrow i} ; & \forall t 0-B T \leqslant t \leqslant T+F T \\
& \forall B I \leqslant i \leqslant F I \\
& \forall 1 \leqslant c t \leqslant C t N
\end{aligned}
$$

In Eq. (6) it is defined the maximum limit of the consumption that can be shifted from period $t$ to period $i$. The constraint represented in Eq. (7) considers a maximum limit for the total consumption that can be shifted from the specific period $t$ to all the shifted periods $i$. To this extent, a determined consumption cluster ct can be able to shift several consumption sets to other periods $i$, but the sum of all these shifted consumption sets must be lower than a determined limit, as imposed by Eq. (7).

$$
\sum_{t-B I \leqslant i}^{i \leqslant t+F I} P_{D R(t, i, c t)} \leqslant P M a x_{D R(t, c t)}^{t} ; \quad \forall t 0-B T \leqslant t \leqslant T+F T
$$

Similarly to the constraint represented in Eq. (7), one can specify a maximum limit for the consumption that can be shifted to each period $i$. In this way, Eq. (8) represents the maximum limit of the consumption shifted for each period $i$, in each consumption cluster $c t$.

$$
\begin{array}{cl}
\sum_{t-B I \leqslant i}^{i \leqslant t+F I} P_{D R(i, t, c t)} \leqslant P M a x_{D R(t, c t)}^{i} ; & \forall t 0-B T \leqslant t \leqslant T+F T \\
& \forall 1 \leqslant c t \leqslant C t N
\end{array}
$$

In addition, one can specify a maximum consumption to be done in period $t$ considering the initially expected demand and the consumption shifting and the reduction amounts that affect the final consumption in that period $t$, as represented in Eq. (9). The need of this constraint is justified by the maximum consumption that technically can be done in each consumption cluster in a certain period $t$, due to contractual power delivering limit established with the network operator.

$$
\begin{aligned}
& P_{\text {Load }(t, c t)}^{\text {Base }}+\sum_{t-B I \leqslant i}^{i \leqslant t+F I}\left[P_{D R(i, t, c t)}-P_{D R(t, i, c t)}\right]-P_{\text {Load }(t, t)}^{N S P} \leqslant P_{\text {Load }(t, c t)}^{\mathrm{Max}} ; \quad \forall t 0-B T \leqslant t \leqslant T+F T \\
& \forall 1 \leqslant c t \leqslant C t N
\end{aligned}
$$

For each consumption cluster $c t$, one must also assure that in each period $t$, the total amount of consumption shifted to other periods (and the consumption reduction performed in the period $t$ ) is lower than the initially expected consumption in the specified $t$ and $c t$, as represented in Eq. (10). Mathematically, this constraint can seem to the one represented in Eq. (7). However, in practice, the subjects, ideas, concerns, and goals are distinct.

$$
\begin{array}{cl}
\sum_{t-B I \leqslant i}^{i \leqslant t+F I} P_{D R(t, i, c t)} \leqslant P_{\text {Load }(t, c t)}^{\text {Base }} ; & \forall t 0-B T \leqslant t \leqslant T+F T \\
& \forall 1 \leqslant c t \leqslant C t N
\end{array}
$$

From the point of view of the VPP, it is considered the possibility of specifying a limit to the relative participation of each consumption cluster in the DR program. Thus, as represented in Eq. (11), a maximum limit $\alpha$, in percentage, is imposed to the total consumption shifting and reduction in each consumption cluster $c t$, in face to the total scheduled consumption shifting and reduction (in all the CtN clusters), in each period $t$.

$$
\begin{array}{cc}
\sum_{t-B I \leqslant i}^{i \leqslant t+F I} P_{D R(t, i, c t)} \leqslant \alpha_{D R}^{M a x} \cdot \sum_{t-B I \leqslant i c t=1}^{i \leqslant t+F I} \sum_{D R(t, i, c t)}^{C t N} P_{D} \quad \forall t 0-B T \leqslant t \leqslant T+F T \\
\forall 1 \leqslant c t \leqslant C t N
\end{array}
$$

In the case of the suppliers, a determined maximum capacity is considered for each period $t$, and for each supplier $s p$, as represented in Eq. (12). Similarly, the maximum capacity of each distributed generation $d g$ is considered in Eq. (13). In some cases, when the DG resources are based on natural sources as the case of wind, the VPP is able to consider that such DG units must be scheduled at the available power. This capability is modeled in Eq. (14) and these constraints are verified for each period $t$ between $t 0-B T$ and $T+F T$.

$$
\begin{array}{cl}
P_{\text {Supply }(t, s p)} \leqslant \operatorname{PMax}_{\text {Supply }(t, s p)} ; \quad \forall t 0-B T \leqslant t \leqslant T+F T \\
& \forall 1 \leqslant s p \leqslant S p N \\
P_{D G(t, d g)} \leqslant \operatorname{PMax}_{D G(t, d g)} ; & \forall t 0-B T \leqslant t \leqslant T+F T \\
& \forall 1 \leqslant d g \leqslant D g N \\
P_{D G(t, d g)}=\operatorname{PMax}_{D G(t, d g)} ; \quad & \forall t 0-B T \leqslant t \leqslant T+F T
\end{array}
$$

In order to limit the contribution of the DG in the resources scheduling, the constraint modeled in Eq. (15) imposes the total DG use $\alpha$, in percentage, at its maximum, in each period $t$. This is intended to give VPP the possibility to limit the DG resources which are usually of large variability and unpredictability.

$$
\begin{aligned}
& \sum_{d g=1}^{D g N} P_{D G(t, d g)} \leqslant \alpha_{D G}^{\mathrm{Max}} \cdot\left[\sum_{t-B I \leqslant i c t=1}^{i \leqslant t+F I} \sum_{D R(t, i, c t)}^{C t N}+\sum_{s p=1}^{S p N} P_{S u p p l y(t, s p)}+\sum_{d g=1}^{D g N} P_{D G(t, d g)}\right] ; \\
& \forall t 0-B T \leqslant t \leqslant T+F T
\end{aligned}
$$

The proposed optimization model is classified as a non-linear problem since the objective function and some constraints are nonlinear. It has been implemented in $\mathrm{TOMLAB}^{\circledR}$ optimization environment [25], running on MATLAB ${ }^{\circledR} 2010$ [26].

TOMLAB $^{\circledR}$ is a general purpose development and modeling environment in MATLAB ${ }^{\circledR}$ for research, teaching and practical solution of optimization problems. In this paper, the optimization problem has been implemented using KNITRO solver. This algorithm 
belongs to the class of interior or barrier methods, and uses trust regions to promote convergence.

The implemented problem, namely considering the case study of this paper, includes 18,365 variables. It is a large number of variables, which can largely increase if we consider more DG units and more consumers. The increasing size of the optimization problem can be critical in the energy resource scheduling which is of upmost importance for the coordination between DGs and DR in order to improve the performance of the entire system. In this context, the use of metaheuristics has been addressed with several advantages in what concerns the computation time and the required computational means [27]. In fact, the large number of DG and DR in the networks tends to increase. The implemented problem could be adapted in order to be solved with a metaheuristic approach, as seen for example in [27].

\section{Case study}

This section presents an illustrative scenario to which the proposed methodology has been applied. The scenario details, including its assumptions and the respective implementation details, are explained.

According to the explanations provided in the previous' sections, it is considered the distributed generation, the demand side, and the suppliers' resources. The resource schedule performed by a VPP minimizes the operation costs, taking into account the resources' constraints for each period. It can be seen in Fig. 3 the available distributed generation in each one of the 96 periods of

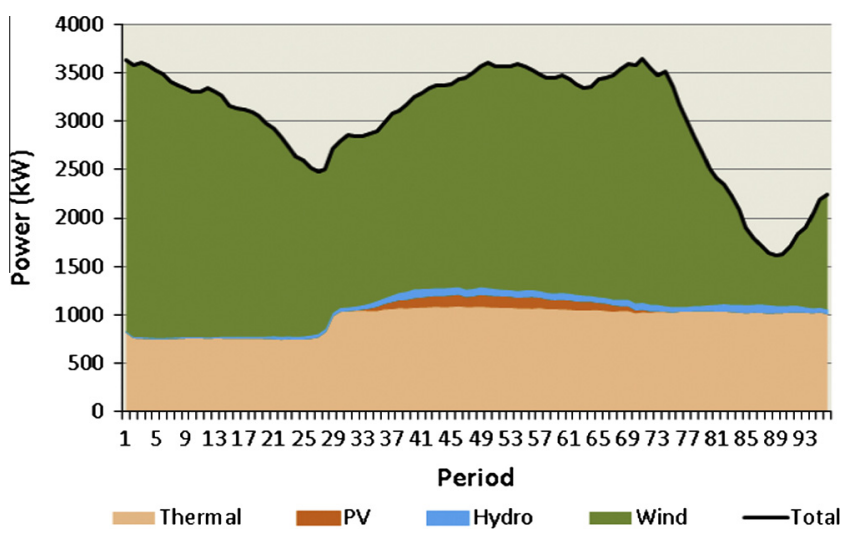

Fig. 3. Distributed generation profiles.
15 min in a day, for each type of DG. This generation profile has been obtained in the context of the real Portuguese power system operation, for thermal, photovoltaic, hydro, and wind generation.

As far as the data used for the demand side is concerned, in Fig. 4 it is presented the consumption profile in each one of the 5 considered consumption clusters. The 96 periods are divided in time horizons defined in Fig. 2. In this way, focusing on the resources schedule optimization, the scheduling horizon includes $10 \mathrm{~h}$ (from period 49 to period 84 ), and the backward (BT) and forward $(F T)$ horizons include $3 \mathrm{~h}$ each (from period 36 to period 37 and from period 85 to period 96 , respectively). The minimum notification period $(M N P)$ is of 32 periods $(8 \mathrm{~h})$.

In the case of the consumption data, it is based on the consumption scenario data presented in [28]. The 218 consumers in the scenario are grouped in 5 consumption clusters. Both the consumption and the available generation data belong to the real context of a specific day in Portugal. The available data include the consumers' demand, the consumption reduction capacity, and the respective due remuneration and costs.

As it can be seen in Fig. 4, two DR events (DR1 and DR2) are considered in the present scenario. These events occur around the daily peak consumption periods. In the periods of each DR event, the VPP has previously established the consumption reduction and shifting available in each consumption cluster, according to the scheme illustrated in Fig. 5. It is also considered the corresponding remuneration to be given to each consumption cluster and to the supply resources.

According to the resources capacities and remuneration values obtained in [28], the scheme illustrated in Fig. 5 has been applied in order to obtain distinct consumption reduction and shifting amounts for different periods. A similar scheme has been applied in order to define the different remuneration prices related to the different defined consumption reduction and shifting power amounts.

In Fig. 5(a) is illustrated the consumption reduction and shifting in and from period $t$ to other periods in the horizon between $t 0-B T$ and $T+F I$. Distinct shifting amounts are defined in distinct periods around or far from $t$. In the case of the illustration presented in Fig. 5(b), a defined single value of consumption can be shifted from period $t$ to other periods close to or far from $t$. Using these two schemes, different consumption reduction and shifting, as well as the respective remuneration prices, have been defined for each one of the implemented 5 consumption clusters, in each period. The details of those values are presented in Tables 1 and 2 .

The consumption parameters, for each consumption cluster, are presented in Table 1. Most of the values belonging to each consumption cluster are equal for all the periods. The same values

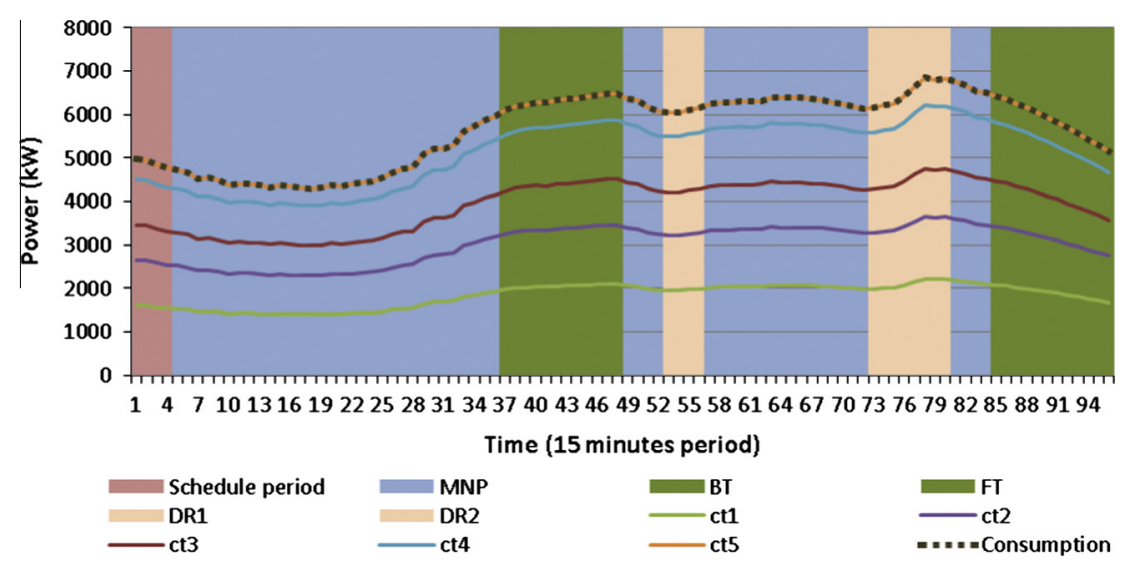

Fig. 4. Consumption profiles. 

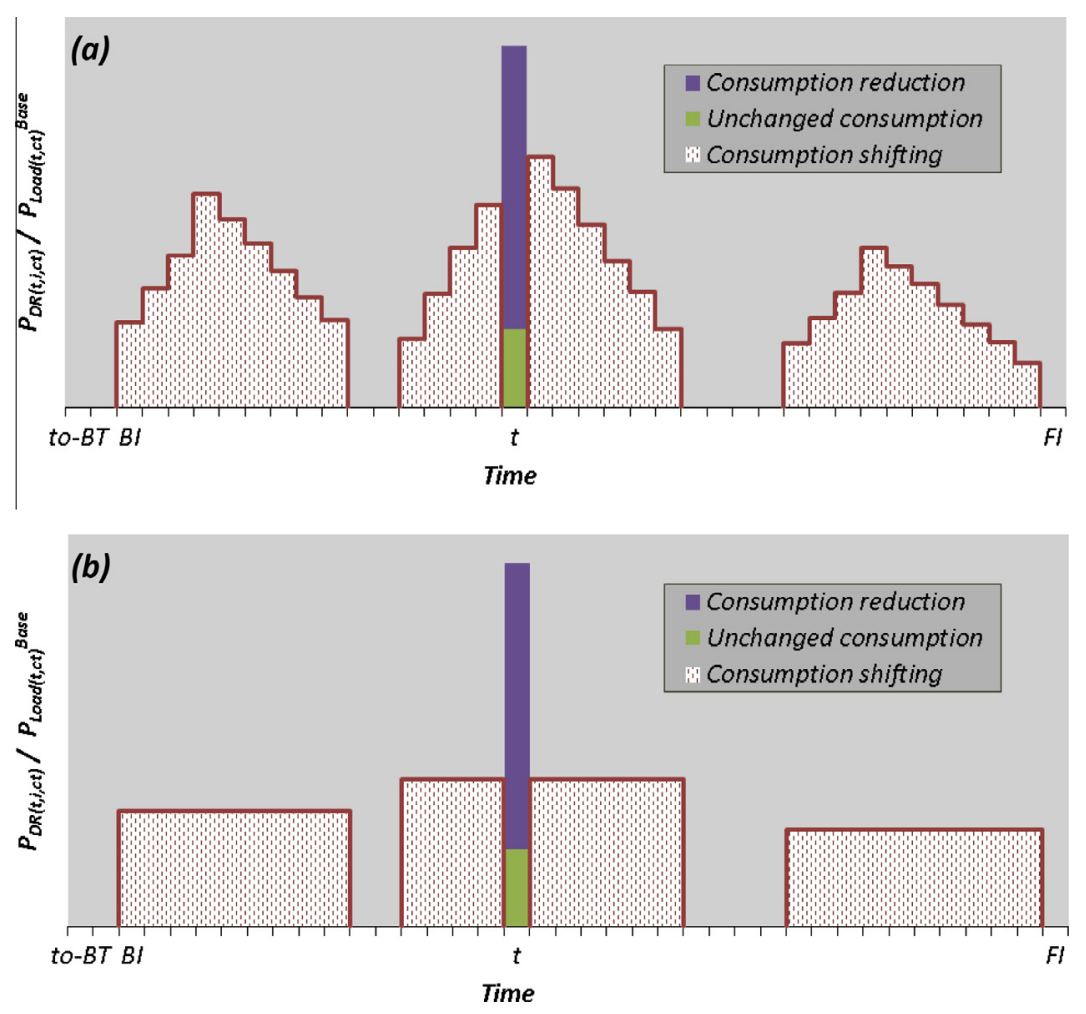

Fig. 5. Consumption reduction and shifting capacities definition scheme.

have been assumed for both the parameters $P M a x_{D R(t, c t)}^{t}$ and $P M a x_{D R}$ ${ }^{i}(t, c t)$, as it can be seen in Table 1 , for each consumption cluster. The base consumption $P_{\text {Laad }(t, c t)}^{\text {aase }}$ has been defined for each consumption cluster $c t$ as a percentage of the total base consumption presented

Table 1

Consumption and supply model parameters values.

\begin{tabular}{|c|c|c|c|c|c|}
\hline \multirow[t]{2}{*}{ Parameter } & \multicolumn{5}{|c|}{ Consumption cluster } \\
\hline & ct1 & $\mathrm{ct} 2$ & ct3 & $\mathrm{ct} 4$ & ct5 \\
\hline$P M a x_{D R(t, c t)}^{t}(\mathrm{~kW})$ & 444.3 & 292.1 & 584.7 & 559.6 & 315.0 \\
\hline $\operatorname{PMax}_{D R(t, c t)}^{i}(\mathrm{~kW})$ & 444.3 & 292.1 & 584.7 & 559.6 & 315.0 \\
\hline Base consumption (\%) & 32.32 & 20.97 & 16.23 & 21.24 & 9.23 \\
\hline Remuneration (m.u./kW) & \multicolumn{5}{|c|}{ According to Table 2} \\
\hline$C_{\text {Load }(t, c t)}^{N S P}($ m.u. $/ \mathrm{kW})$ & \multicolumn{5}{|c|}{8} \\
\hline$P_{\text {Load }(t, c t)}^{\text {Max }}(\mathrm{kW})$ & \multicolumn{5}{|c|}{$120 \%$ of the base consumption } \\
\hline$\alpha_{D R}^{\operatorname{Max}}(\%)$ & \multicolumn{5}{|c|}{80} \\
\hline
\end{tabular}

in Fig. 4. The final maximum consumption in each cluster, in each period $t$, has been defined as $120 \%$ of the respective base consumption.

The large amount of values concerning the parameter $\operatorname{PMax}_{D R}^{t \rightarrow i}(t, i, c t)$, which represents the maximum consumption that can be shifted from $t$ to $i$ (reduced in period $t$, for $i=t$ ), are detailed in Table 2 and Table 3, respectively for $t=49$ to $t=52$ and for $t=69$ to $t=76$. For each period $t$ of the scheduling horizon $T$ the shifting possibilities are presented, in each consumption cluster. As an example, the text " $50 ; 0.05 \rightarrow 37,52: 56$ " in the row of $t=49$ of Table 2, means that it is possible to shift (reduce) $50 \mathrm{~kW}$ of consumption from period 49 , with a remuneration of 0.05 , to period 37 , and to all periods between 52 and 56. As explained in Section 3 , the total shifted consumption from period $t$ is limited by the constraint represented in Eq. (7). In this case, the sum of $140 \mathrm{~kW}$ $(7 * 20 \mathrm{~kW})$ will be limited to $63.47 \mathrm{~kW}\left(\operatorname{PMax}_{D R(t, c t)}^{t}\right.$ for $c t=1$, according to Table 1 ).

Table 2

Consumption shifting and reduction amounts and remuneration values.

\begin{tabular}{|c|c|c|c|c|c|}
\hline \multirow[t]{2}{*}{$t$} & \multicolumn{5}{|c|}{ Consumption cluster } \\
\hline & ct1 & ct2 & ct3 & ct4 & ct5 \\
\hline 49 & $20 ; 0.06 \rightarrow 67: 70$ & $\begin{array}{l}45 ; 0.10 \rightarrow 46,52: 56 \\
45 ; 0.11 \rightarrow 49 \\
146.04 ; 0.10 \rightarrow 47: 48,50: 51\end{array}$ & $\begin{array}{l}90 ; 0.23 \rightarrow 46,52: 56 \\
90 ; 0.24 \rightarrow 49 \\
292.35 ; 0.23 \rightarrow 47: 48,50: 51\end{array}$ & $\begin{array}{l}50 ; 0.05 \rightarrow 37,52: 56 \\
50 ; 0.06 \rightarrow 49 \\
186.54 ; 0.05 \rightarrow 38: 48,50: 51\end{array}$ & - \\
\hline 50 & $20 ; 0.06 \rightarrow 67: 70$ & $\begin{array}{l}45 ; 0.10 \rightarrow 47,53: 57 \\
45 ; 0.11 \rightarrow 50 \\
146.04 ; 0.10 \rightarrow 48: 49,51: 52\end{array}$ & $\begin{array}{l}90 ; 0.23 \rightarrow 47,53: 57 \\
90 ; 0.24 \rightarrow 50 \\
292.35 ; 0.23 \rightarrow 48: 49,51: 52\end{array}$ & $\begin{array}{l}50 ; 0.05 \rightarrow 38,53: 57 \\
50 ; 0.06 \rightarrow 50 \\
186.54 ; 0.05 \rightarrow 39: 49,51: 52\end{array}$ & - \\
\hline 51 & $20 ; 0.06 \rightarrow 67: 70$ & $\begin{array}{l}45 ; 0.10 \rightarrow 48,54: 58 \\
45 ; 0.11 \rightarrow 51 \\
146.04 ; 0.10 \rightarrow 49: 50,51: 52\end{array}$ & $\begin{array}{l}90 ; 0.23 \rightarrow 48,54: 58 \\
90 ; 0.24 \rightarrow 51 \\
292.35 ; 0.23 \rightarrow 49: 50,51: 52\end{array}$ & $\begin{array}{l}50 ; 0.05 \rightarrow 39,54: 58 \\
50 ; 0.06 \rightarrow 51 \\
186.54 ; 0.05 \rightarrow 40: 50,52: 53\end{array}$ & - \\
\hline 52 & $20 ; 0.06 \rightarrow 67: 70$ & $\begin{array}{l}45 ; 0.10 \rightarrow 49,55: 59 \\
45 ; 0.11 \rightarrow 52 \\
146.04 ; 0.10 \rightarrow 50: 51,53: 54\end{array}$ & $\begin{array}{l}90 ; 0.23 \rightarrow 49,55: 59 \\
90 ; 0.24 \rightarrow 52 \\
292.35 ; 0.23 \rightarrow 50: 51,53: 54\end{array}$ & $\begin{array}{l}50 ; 0.05 \rightarrow 40,55: 59 \\
50 ; 0.06 \rightarrow 52 \\
186.54 ; 0.05 \rightarrow 41: 51,53: 54\end{array}$ & - \\
\hline
\end{tabular}


Table 3

Consumption shifting and reduction amounts and remuneration values.

\begin{tabular}{|c|c|c|c|c|c|}
\hline \multirow[t]{2}{*}{$t$} & \multicolumn{5}{|l|}{ Consumption cluster } \\
\hline & $\mathrm{ct} 1$ & ct2 & ct3 & ct4 & ct5 \\
\hline 69 & $\begin{array}{l}20 ; 0.06 \rightarrow 66,72: 76 \\
20 ; 0.07 \rightarrow 69 \\
63.47 ; 0.06 \rightarrow 67: 68,70: 71\end{array}$ & - & - & - & $\begin{array}{l}35 ; 0.12 \rightarrow 53,72 \\
35 ; 0.12 \rightarrow 69 \\
111.58 ; 0.12 \rightarrow 54: 68,70: 71\end{array}$ \\
\hline 70 & $\begin{array}{l}20 ; 0.06 \rightarrow 67,73: 77 \\
20 ; 0.07 \rightarrow 70 \\
63.47 ; 0.06 \rightarrow 68: 69,71: 72\end{array}$ & - & - & - & $\begin{array}{l}35 ; 0.12 \rightarrow 54,73 \\
35 ; 0.12 \rightarrow 70 \\
111.58 ; 0.12 \rightarrow 55: 69,71: 72\end{array}$ \\
\hline 71 & $\begin{array}{l}20 ; 0.06 \rightarrow 68,74: 78 \\
20 ; 0.07 \rightarrow 71 \\
63.47 ; 0.06 \rightarrow 69: 70,72: 73\end{array}$ & - & - & - & $\begin{array}{l}35 ; 0.12 \rightarrow 55,74 \\
35 ; 0.12 \rightarrow 71 \\
111.58 ; 0.12 \rightarrow 56: 70,72: 73\end{array}$ \\
\hline 72 & $\begin{array}{l}20 ; 0.06 \rightarrow 69,75: 79 \\
20 ; 0.07 \rightarrow 72 \\
63.47 ; 0.06 \rightarrow 70: 71,73: 74\end{array}$ & - & - & - & $\begin{array}{l}35 ; 0.12 \rightarrow 56,75 \\
35 ; 0.12 \rightarrow 72 \\
111.58 ; 0.12 \rightarrow 57: 71,73: 74\end{array}$ \\
\hline 73 & $\begin{array}{l}20 ; 0.06 \rightarrow 74: 76 \\
20 ; 0.07 \rightarrow 73\end{array}$ & - & - & - & $\begin{array}{l}35 ; 0.12 \rightarrow 57,65 \\
111.58 ; 0.12 \rightarrow 58: 64\end{array}$ \\
\hline 74 & $\begin{array}{l}20 ; 0.06 \rightarrow 75: 77 \\
20 ; 0.07 \rightarrow 74\end{array}$ & - & - & - & $\begin{array}{l}35 ; 0.12 \rightarrow 58,66 \\
111.58 ; 0.12 \rightarrow 59: 65\end{array}$ \\
\hline 75 & $\begin{array}{l}20 ; 0.06 \rightarrow 76: 78 \\
20 ; 0.07 \rightarrow 75\end{array}$ & - & - & - & $\begin{array}{l}35 ; 0.12 \rightarrow 59,67 \\
111.58 ; 0.12 \rightarrow 60: 66\end{array}$ \\
\hline 76 & $\begin{array}{l}20 ; 0.06 \rightarrow 77: 79 \\
20 ; 0.07 \rightarrow 76\end{array}$ & - & - & - & $\begin{array}{l}35 ; 0.12 \rightarrow 60,68 \\
111.58 ; 0.12 \rightarrow 61: 67\end{array}$ \\
\hline
\end{tabular}

In accordance with the information given in Fig. 4, two DR events (DR1 and DR2) are considered in the present scenario. These events occur between periods 49 and 52 (DR1 - 1 h duration), and between periods 69 and 76 (DR2 - 2 h duration). The VPP is able to schedule the available consumption reduction and shifting capacity available in each one of the 5 consumption clusters (ct1-ct5).

In what concerns the distributed generation and the suppliers that are available for the VPP to consider in the operation of the

Table 4

Suppliers and distributed generation model parameters values.

\begin{tabular}{lllll}
\hline Resource & \multicolumn{2}{l}{$\begin{array}{l}\text { Cost function } \\
\text { parameters }\end{array}$} & Capacity (kW) & $\alpha_{D G}^{\text {Max }}(\%)$ \\
\cline { 2 - 3 } & Quadratic & Linear & & \\
\hline Regular supplier & - & 0.07 & According to Fig. 3 & 60 \\
Additional supplier & - & 0.18 & & \\
Thermal & 0.0034 & 0.12 & & \\
PV & 0.0045 & 0.02 & & \\
Hydro & 0.0072 & 0.06 & & \\
Wind & 0.0021 & 0.04 & & \\
\hline
\end{tabular}

network, Table 4 presents the information regarding the value of each parameter in the implemented case study. The parameters in this table refer to the four types of distributed generation and to the supplier power that is divided into a regular amount of power and an additional amount of power, available at distinct prices.

For the results obtained in the present case study, three distinct scenarios - ScenA, ScenB, and ScenC - have been implemented. In both the ScenA and ScenB, an unexpected unavailability of the whole wind power in period 50 (DR1 event in Fig. 4) is simulated. In the case of ScenA, this unavailability is only compensated by distributed generation and supplier resources, whereas in the case of ScenB, the VPP is able to make use of demand response.

This wind unavailability corresponds to $2329 \mathrm{~kW}$. In the case of ScenC, a second unavailability of wind power period is considered in period 70 (DR2 event in Fig. 4). It is considered that only $20 \%$ of the initial expected wind power is available, which corresponds to an availability of $492 \mathrm{~kW}$. In the scenario ScenC, it is considered that the wind unavailability applies to both DR1 and DR2 event periods. The results' presentation and analysis is undertaken in Section 5.

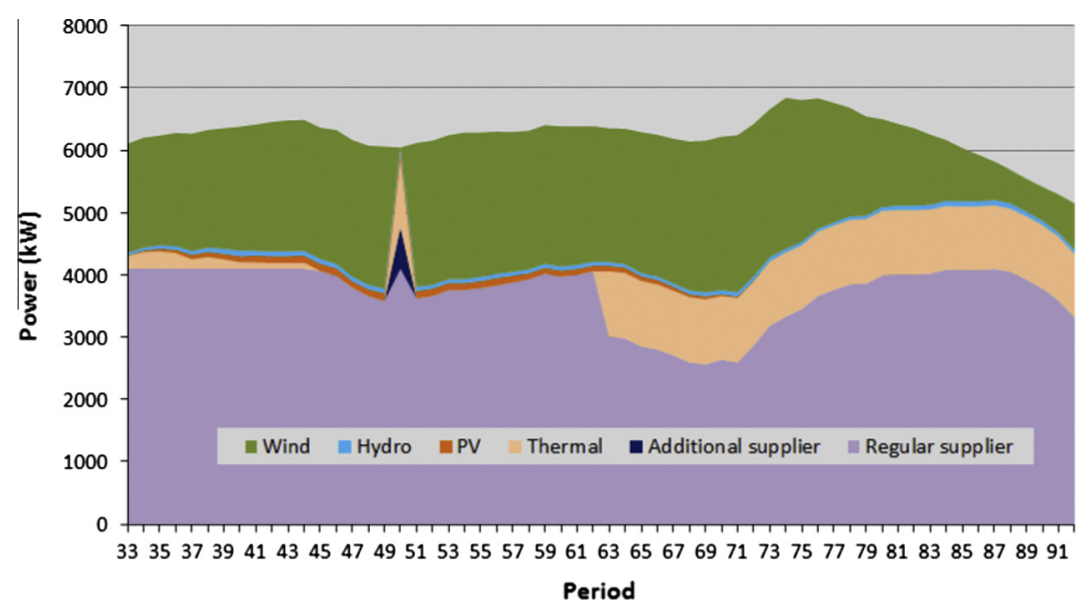

Fig. 6. Resource schedule in ScenA. 


\section{Results analysis}

This section presents and discusses the results obtained with the application of the proposed methodology to the case study presented in Section 4. Three distinct scenarios have been implemented as explained above. The results regarding ScenA are presented in Section 5.1, the ones regarding ScenB are presented in Section 5.2, and the ones referring to ScenC are presented in Section 5.3. Section 5.4 focuses on the comparison of the results in each scenario in what concerns the resources' use.

\subsection{Resources schedule in scenario ScenA}

The implemented scenario concerning ScenA is related to the unavailability of $2329 \mathrm{~kW}$ of wind power generation, considering all the previously expected wind power availability. The obtained resources schedule is presented in Fig. 6. In order to focus on the
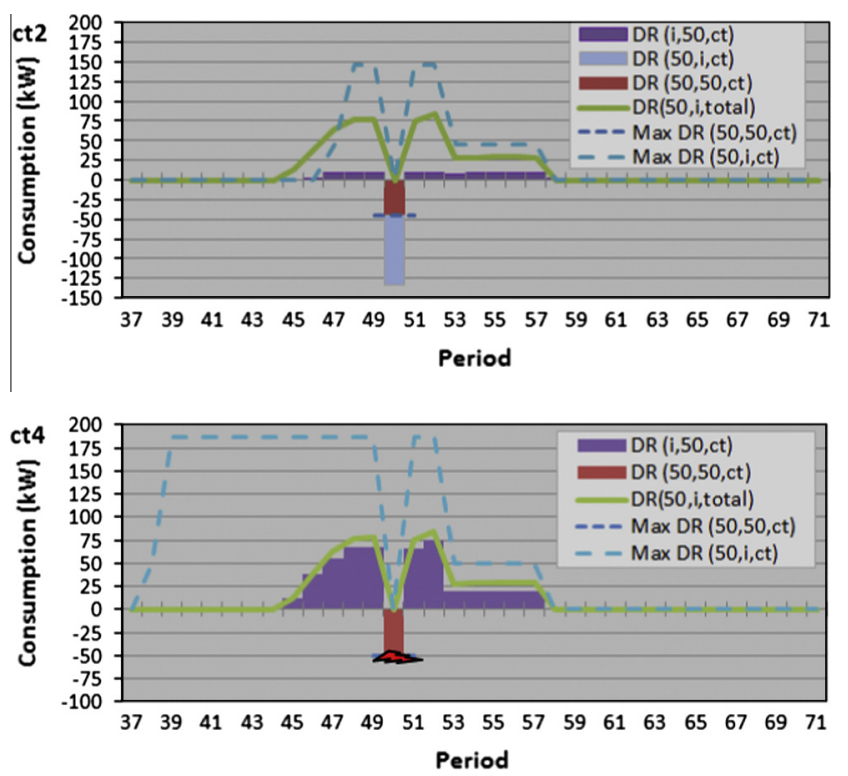

Fig. 7. Consumption reduction and shifting in each consumption cluster, in ScenB. envisaged periods (the ones that have a resources schedule distinct from the base scenario), Fig. 6 only presents the periods after period 33.

It can be seen that in period 50 the wind power shortage is covered by the use of regular and additional supplier amount, and also thermal generation that otherwise would not be used in period 50 . It can also be seen that the VPP, which previously establishes contracts with electricity suppliers, has a reduced amount of regular supplier power in periods after period 50 .

It can be concluded that the additional supplier power that the VPP has for period 50 was adequately used in this period in order to face the operation's constraint imposed by the new wind power amount. As previously referred, the demand response resources are not considered in this ScenA.

\subsection{Resources schedule in scenario ScenB}

Focusing on the ScenB scenario, it differs from ScenA in the fact that the demand response resources are now available for the VPP in order to meet the wind power unavailability in period 50 . In this way, the focus here is given to the use of demand response resources in this scenario, as it can be seen in Fig. 7 . The results concerning the generation resources use can be seen in Section 5.4. For better explanation of the results concerning DR resources, the Fig. 7 only presents periods $37-71$.

In order to give further detail on the consumption shifting schedule, Fig. 7 presents the demand resources (reduction and shifting) schedule, only including the two scheduled consumption clusters (ct2 and ct4). It can be seen, for each consumption cluster, the reduction and shifted amount in period 50 , and the new consumption that appears in each period due to the consumption shifting schedule. It is also possible to see the maximum consumption and shifting capacity, so one can have an idea on how much consumption shifting could be additionally scheduled. The green line shows the sum of the consumption shifting that has been scheduled for each period.

From Fig. 6, it can be seen all the available consumption shifting and reduction in consumption cluster ct2. The whole available consumption reduction capacity has been used, whereas only a reduced capacity of consumption shifting is scheduled to periods close, and after and before period 50 . In the consumption cluster ct4, it has been scheduled the whole available consumption

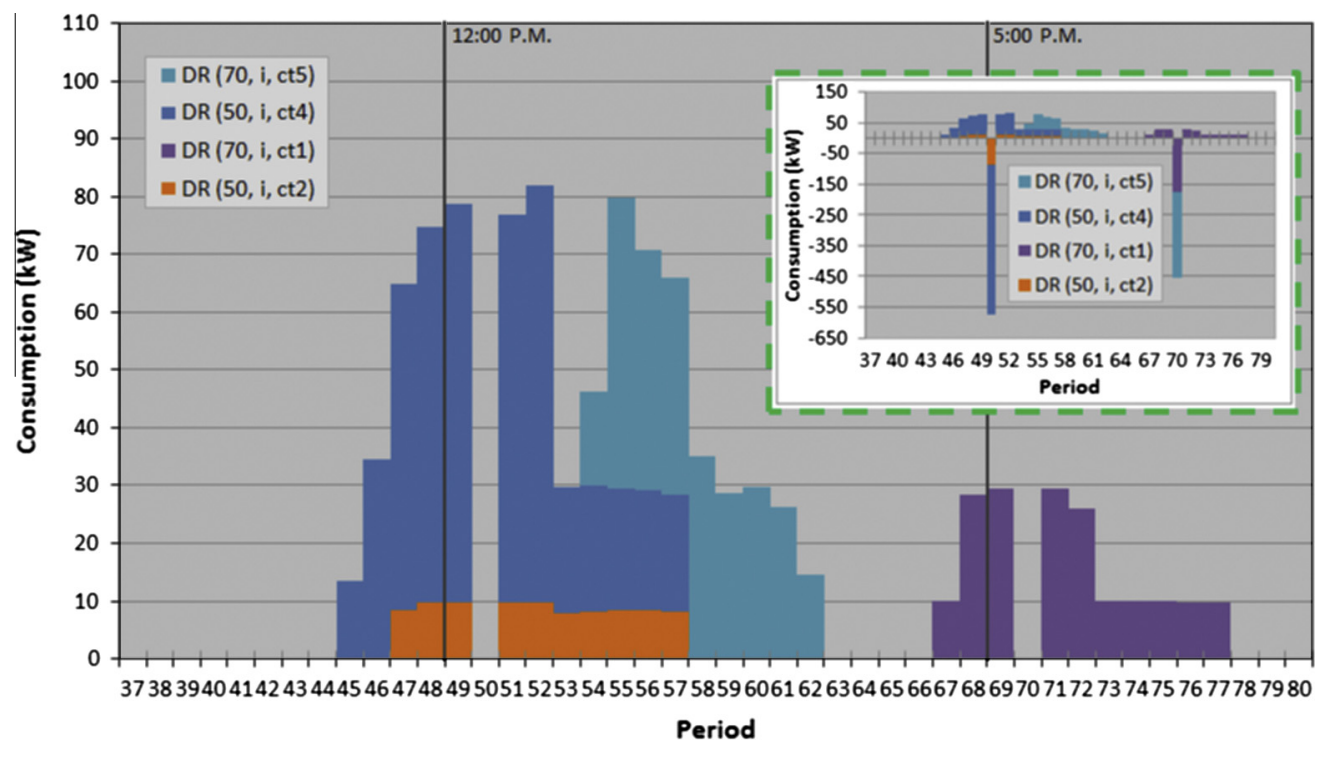

Fig. 8. Consumption shifting in each consumption cluster, in ScenC. 


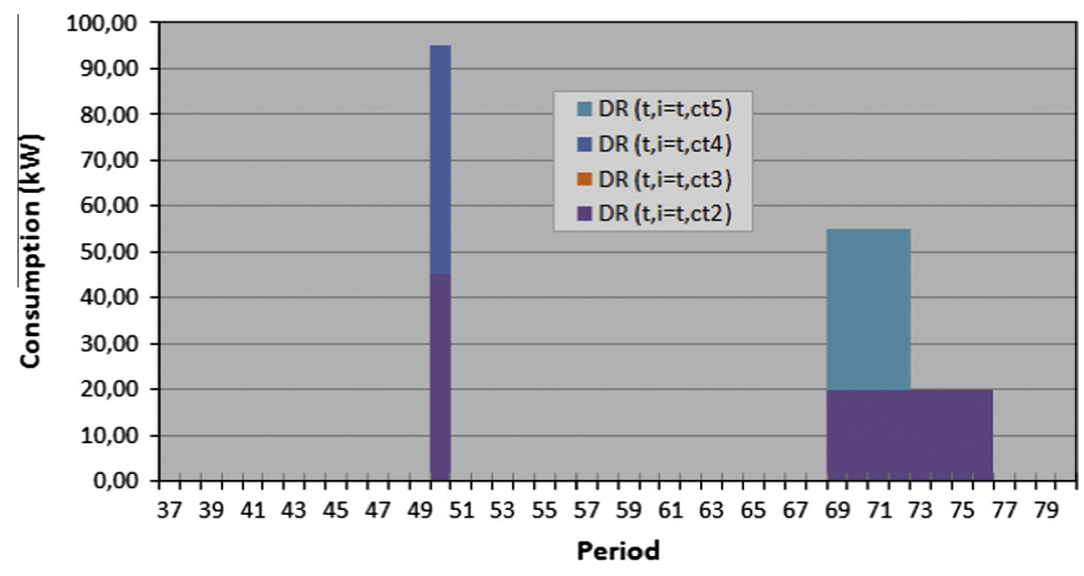

Fig. 9. Consumption reduction in each consumption cluster, in ScenC.

reduction capacity. In this case, in order to keep the resolution of the graph, the $y y$ axis minimum value has been defined at -100 while, in fact, the shifted consumption from period 50 is equal to $510 \mathrm{~kW}$. There is a great consumption shifting remaining capacity which belongs mainly to periods before period 50 but also to periods after period 50 . In both cases, consumption cluster ct 4 is able to shift consumption to periods close to period 50 .

In spite of the fact that there is a large amount of remaining consumption shifting capacity, it has been limited by the constraint presented in Eq. (11). In the present case study, $\alpha_{D R}^{M a x}$ is equal to $80 \%$, which means that a certain consumption cluster is not allowed to have a consumption reduce and shifting schedule higher than $80 \%$ of the total consumption reduction and shifting scheduled, in all the consumption clusters.

\subsection{Resources schedule in scenario ScenC}

After discussing the results for ScenA and ScenB, the wind generation unavailability in period 50 is kept and an additional wind power unavailability that leads to only $492 \mathrm{~kW}$ of wind power available, in period 70 (between 17:15 p.m. and 17:30 p.m.) is to be considered. These two DR events occurring in the same simulation lead up to ScenC.

In order to focus on the resources' schedule results showing the shifting results from the DR events occurring at periods 50 and 70 , the results for the ScenC scenario are presented for periods 37-80, as in the case of Fig. 8. Looking at the results shown in Fig. 8, the total consumption reduction in each one of the DR event periods can be seen. It can also be observed the total amount of consumption shifted to each period from periods 50 and 70. It is important to note that, even of a reduced amount, it has been scheduled consumption shifting to periods after period 37 and before period 50 . Moreover, while the consumption shifted from period 50 in consumption clusters ct 2 and ct 4 is done for periods close (before and after) to period 50 , in the case of consumption cluster ct 1 the consumption is shifted for periods far from period 50. In fact, the consumption shifted in ct 1 from period 50 is scheduled to periods very close (before) period 70 (the one of the second DR event).

The results shown in Fig. 8 are focused on the positive ones (only the consumption shifting incoming in each period). For overall reference, a more complete version of the graph presented in Fig. 8 is shown at the top right (with a green dashed line border) of this figure. Also for reference, 12:00 P.M. and 5:00 P.M. are signalled.

The previous results only concerned the shifting consumption amounts. In what regards the consumption reduction (consumption that is not shifted nor performed in the predicted period), Fig. 9 gives the results for each consumption cluster. The presented values concern the two DR events scheduling. It is interesting to note, for example, the case of periods 68-76. While some consumption has been shifted from period 70 to these periods, in these ones it is also scheduled some consumption reduction in order to accommodate the incoming consumption, as economically scheduled.
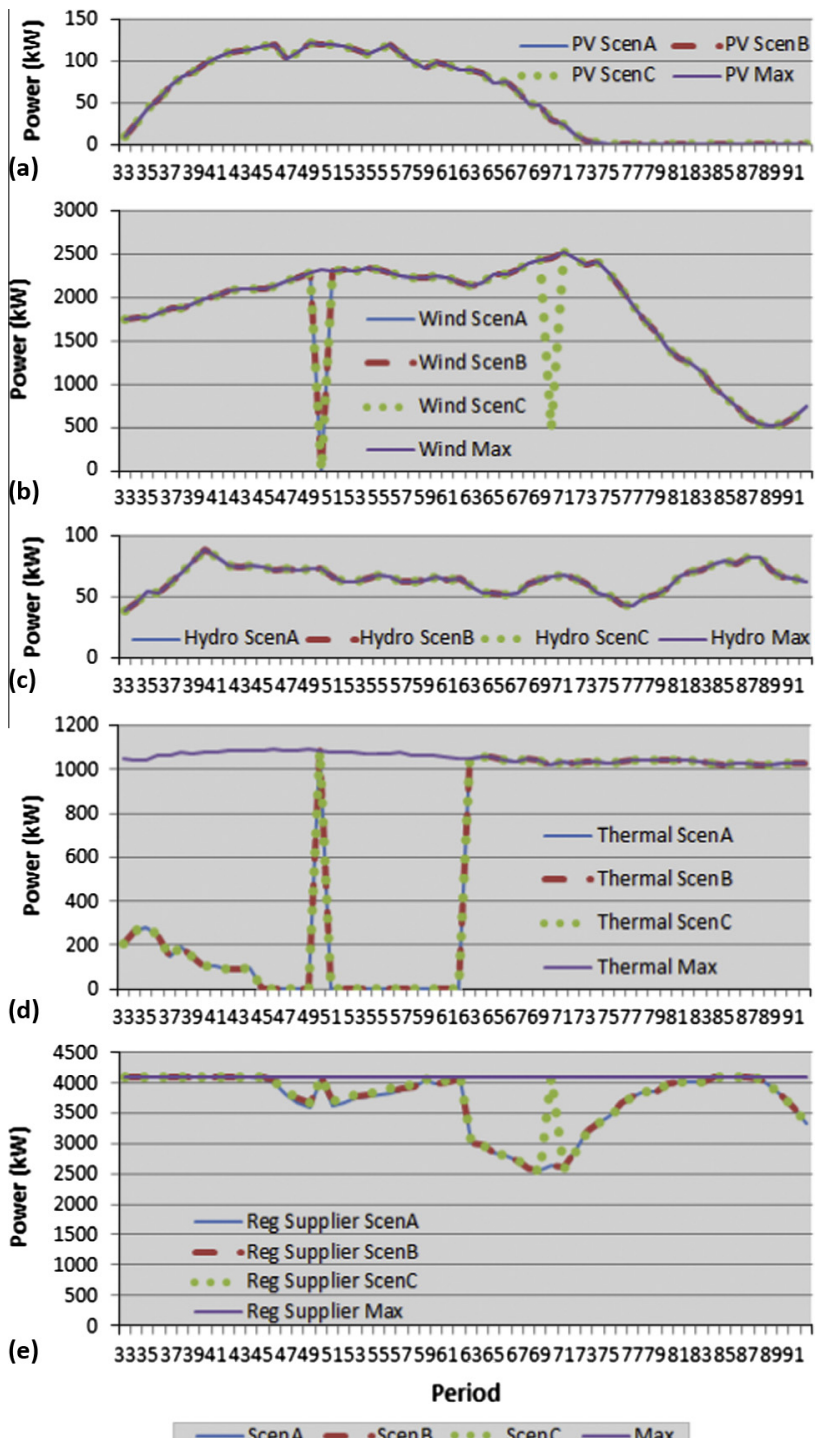

Fig. 10. Generation resources use comparison. 


\subsection{Comparison of the results in each scenario}

In order to perform a comparison of the resources' use in the three scenarios, Fig. 10 focuses on the generation resources results, whereas Fig. 11 focuses on the results concerning demand response resources.

From Fig. 10, one can see the results of the use of each generation resource - (a) PV, (b) Wind, (c) Hydro, (d) Thermal, and (e) Regular Supplier - in each one of the three implemented scenarios. The maximum amount available for each resource is also presented. The focus is given to periods after period 33, as in Fig. 6. One can see that hydro and PV resources are always used at its maximum capacity. The same can be said for the case of wind generation, with exception to the DR event periods in which the available wind power is reduced. Due to the change in the price of Regular Supplier after period 63, thermal based generation is used after period 63 and also in the period of the first DR event in order to meet the wind unavailability. The regular Supplier power is scheduled according to its price; moreover, it can be seen its contribution to meet the wind power unavailability in the periods of the two DR events.

In what concerns the scheduling of demand response resources, one can see its use in each scenario, as well as the maximum available power in Fig. 11. These results include the total amounts concerning consumption reduction and consumption shifting, in each
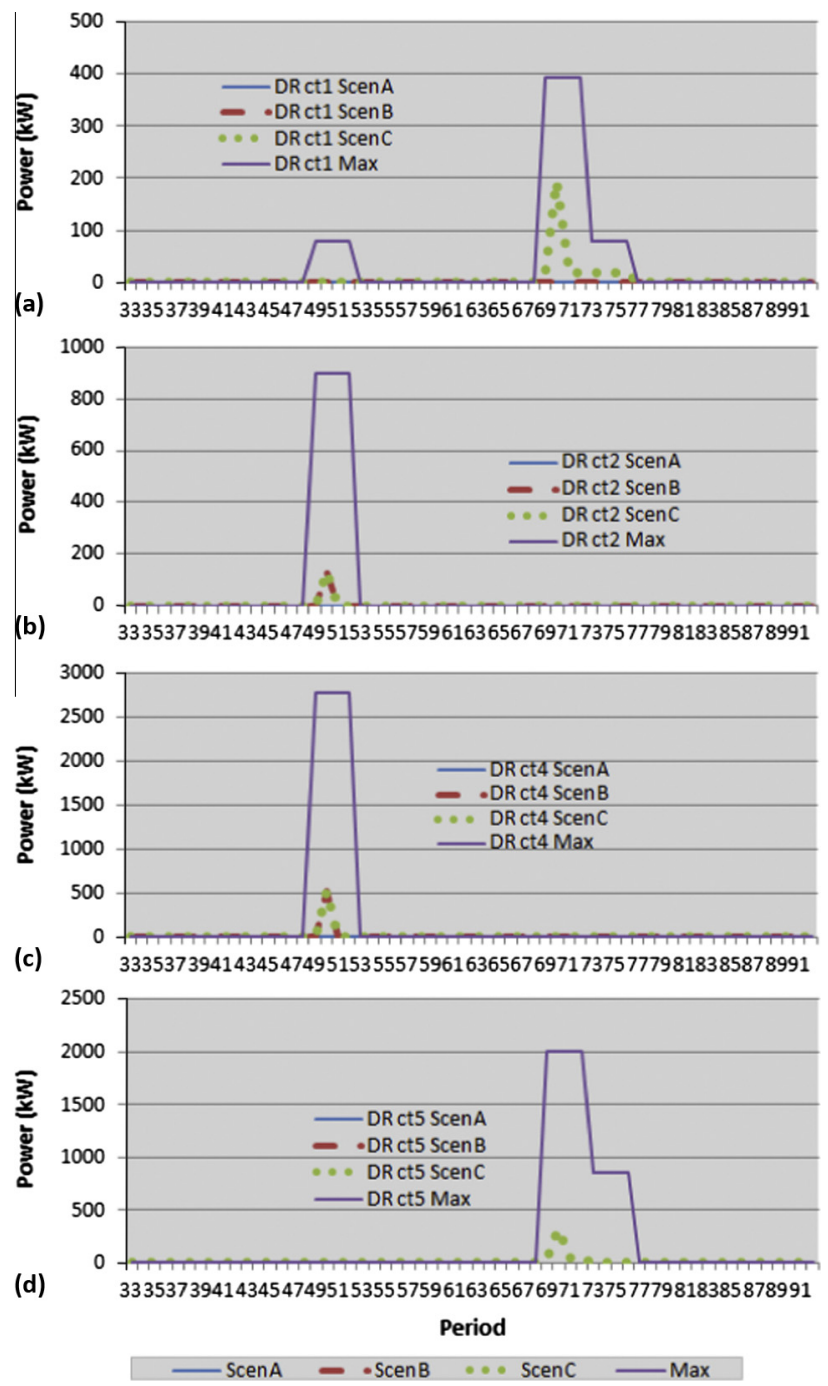

Fig. 11. Demand response resources use comparison. consumption cluster - (a) ct1, (b) ct2, (c) ct4, and (d) ct5. The demand response available in consumption cluster ct 3 is not used in the implemented scenarios. While ct 2 and ct 4 are scheduled to meet the needs of DR event DR1, ct1 and ct5 are scheduled in the occurrence of DR event DR2. Also, one can see that, obviously, the participation of DR resources in the case of DR event DR2 only occurs in ScenC.

\section{Conclusions}

The use of the consumption flexibility, namely in the implementation of demand response programs, is a very valuable resource. The electricity generation using distributed generation resources has assumed an increasing importance in operation of power systems. However, additional models and methodologies are needed in order to better address the consumer and distributed generation owners' constraints so to take full advantages of them.

The work presented in this paper has addressed the scheduling of the available opportunities of consumption reduction and shifting, and of distributed generation. These resources are managed by a Virtual Power Player (VPP) that owns the distribution network and is able to manage the available distributed resources together with the use of the power that can be obtained from the supply side, namely through the medium voltage network.

The developed optimization model aims at minimizing the VPP operation costs while considering several consumption reduction and shifting constraints which concern the maximum amount of consumption to be scheduled in each consumption cluster, in each period. Load balance in each period and in each consumption cluster is also considered in the balance equations that also consider the use of distributed generation of several types. The developed model is characterized by several dynamic input parameters in the optimization model.

A case study with 218 consumers from 5 consumption clusters and 4 distributed generation types has been presented. Three distinct scenarios with 2 DR events have been considered. The scenarios are characterized by 96 periods of $15 \mathrm{~min}$. It has been demonstrated the application of the proposed methodology and of the optimization algorithm in terms of resources scheduling and of VPP operation costs (remuneration of the resources).

The advantages of using the proposed method have been proved. When declaring a DR event, namely due to an unavailability of wind generation, the consumers can be able to reduce the consumption by shifting part of it to other periods, giving higher operation flexibility to the VPP. In this way, the VPP avoids paying for the non supplied power to the envisaged consumers. The consumers benefit with the remuneration that they receive due to the participation in the DR event, whereas the distributed generation units' owners benefit from the remuneration due to the actual generation output. The use of DR and DG can be, in this way, a competitive resource in the context of the VPP operation, with advantages for all the players, and taking into account the technical and behavioral constraints of the resources.

\section{Acknowledgements}

The research leading to these results has received funding from the People Programme (Marie Curie Actions) of the European Union's Seventh Framework Programme FP7/2007-2013/under project ELECON, REA grant agreement No 318912.

This work is also supported by FEDER Funds through the "Programa Operacional Factores de Competitividade - COMPETE" program and by National Funds through FCT "Fundação para a Ciência e a Tecnologia" under the projects FCOMP-01-0124-FEDER: PEst-OE/EEI/UI0760/2015, PTDC/SEN-ENR/122174/2010, and 
SFRH/BD/80183/2011 (P. Faria PhD); by the SASGER-MeC, Project No. NORTE-07-0162-FEDER-000101, co-funded by COMPETE under FEDER Programme; and by the GID-MicroRede, Project No. 34086, co-funded by COMPETE under FEDER via QREN Programme. The present work is also developed under the EUREKA - ITEA2 Project SEAS with project number 12004.

\section{References}

[1] US Department of Energy. Benefits of demand response in electricity markets and recommendations for achieving them. Report to the United States Congress. February 2006.

[2] MacCormack J, Zareipour H, Rosehart WD. Long-term market equilibrium model with strategic, competitive, and inflexible generation. IEEE Trans Power Syst Nov. 2012;27(4):2291-2.

[3] Woo C, Greening L. Special issue demand response resources: the US and international experience introduction. Energy 2010;35:1515-7.

[4] Siano Pierluigi. Demand response and smart grids-a survey. Renew Sust Energy Rev 2014;30:461-78. http://dx.doi.org/10.1016/j.rser.2013.10.022. ISSN 1364-0321.

[5] Faria P, Vale Z. Demand response in electrical energy supply: an optimal real time pricing approach. Energy 2011;36:5374-84.

[6] Faria Pedro, Soares Tiago, Vale Zita, Morais Hugo. Distributed generation and demand response dispatch for a virtual power player energy and reserve provision. Renew Energy 2014;66:686-95.

[7] Chicco G, Napoli R, Postulache P, Scutariu M, Toader C. Customer characterization options for improving the tariff offer. IEEE Trans Power Syst 2003;18(1).

[8] FERC. FERC Order No. 719. <http://www.ferc.gov/whats-new/comm-meet/ 2009/071609/E-1.pdf>.

[9] European Commission. Incorporating demand side flexibility, in particular demand response, in electricity markets. 2013. <http://ec.europa.eu/energy/ gas_electricity/doc/com_2013_public_intervention_swd07_en.pdf> [accessed in April 2014].

[10] European Commission. European SmartGrids Technology Platform - vision and strategy for Europe's electricity networks of the future. European Communities, April; 2010.

[11] Morais Hugo, Faria Pedro, Vale Zita. Demand response design and use based on network locational marginal prices. Int J Electr Power Energy Syst October 2014;61:180-91.

[12] Christian Gils Hans. Assessment of the theoretical demand response potential in Europe. Energy 2014;67:1-18.
13] Ravindra Kumudhini, Iyer Parameshwar P. Decentralized demand-supply matching using community microgrids and consumer demand response: a scenario analysis. Energy 2014.

[14] Bartusch Cajsa, Alvehag Karin. Further exploring the potential of residential demand response programs in electricity distribution. Appl Energy July 2014;125(15):39-59.

[15] Vlot MC, Knigge JD, Slootweg JG. Economical regulation power through load shifting with smart energy appliances. IEEE Trans Smart Grid 2013:4(3):1705-12.

[16] Mehta Nishant, Sinitsyn Nikolai A, Backhaus Scott, Lesieutre Bernard C. Safe control of thermostatically controlled loads with installed timers for demand side management. Energy Convers Manage 2014;86:784-91.

[17] Huang D, Billinton R. Effects of load sector demand side management applications in generating capacity adequacy assessment. IEEE Trans Power Syst 2012;27(1):335-43.

[18] Kwag Hyung-Geun, Kim Jin-O. Reliability modeling of demand response considering uncertainty of customer behavior. Appl Energy 2014;122(1):24-33.

19] Silva M, Morais H, Vale Z An integrated approach for distributed energy resource short-term scheduling in smart grids considering realistic power system simulation. Energy Convers Manage 2012;64:273-88.

20] Zhang Linfeng, Gari Nicolae, Hmurcik Lawrence V. Energy management in microgrid with distributed energy resources. Energy Convers Manage 2014;78:297-305.

[21] Karl Critz D, Busche Sarah, Connors Stephen. Power systems balancing with high penetration renewables: the potential of demand response in Hawaii. Energy Convers Manage 2013;76:609-19.

[22] Mazidi Mohammadreza, Zakariazadeh Alireza, Jadid Shahram, Siano Pierluigi. Integrated scheduling of renewable generation and demand response programs in a microgrid. Energy Convers Manage 2014;86:1118-27.

[23] Hai Lu, Alanne Kari, Martinac Ivo. Energy quality management for building clusters and districts (BCDs) through multi-objective optimization. Energy Convers Manage 2014;79:525-33.

[24] Roberts David. How to get to a fully renewable power system. <http://grist org/renewable-energy/2011-05-26-how-to-get-to-a-fully-renewable-powersystem/>; 2014

[25] Holmstrom K, Goran A, Edvall M. User's guide for TOMLAB 7. <http://tomopt. com/docs/TOMLAB.pdf>; 2010.

[26] MATLAB. Natick, Massachusetts: The MathWorks Inc.; 2010.

[27] Faria P, Soares J, Vale Z, Morais H, Sousa T, Modified particle swarm optimization applied to integrated demand response and DG resources scheduling. IEEE Trans Smart Grid 2013;4(1):606-16.

[28] Faria P, Vale Z. Demand response programs definition using demand price elasticity to define consumers aggregation for an improved remuneration structure. In: 4th IEEE PES ISGT Europe; October 2013. p. 7-10. 